\title{
Humpback whale song occurs extensively on feeding grounds in the western North Atlantic Ocean
}

\author{
Elizabeth T. Vu ${ }^{1,4, *}$, Denise Risch ${ }^{1}$, Christopher W. Clark ${ }^{2}$, Shonda Gaylord ${ }^{1}$, \\ Leila T. Hatch ${ }^{3}$, Michael A. Thompson ${ }^{3}$, David N. Wiley ${ }^{3}$, Sofie M. Van Parijs ${ }^{1,2}$ \\ ${ }^{1}$ Northeast Fisheries Science Center, 166 Water Street, Woods Hole, Massachusetts 02543, USA \\ ${ }^{2}$ Bioacoustics Research Program, Cornell University, New York 14850, USA \\ ${ }^{3}$ Stellwagen Bank National Marine Sanctuary, NOAA, 175 Edward Foster Road, Scituate, Massachusetts 02066, USA \\ ${ }^{4}$ Present address: Scripps Institution of Oceanography, University of California, San Diego, 9500 Gilman Drive, \\ Mail Code 0205, La Jolla, California 92093-0208, USA
}

\begin{abstract}
Male humpback whales produce complex, patterned songs that are traditionally heard on their breeding grounds. Short-term studies demonstrated that they also sing along migration routes and on higher-latitude feeding grounds. This study expands the current understanding of feeding-ground song by providing yearlong views of singing activity. Acoustic recordings were made in Stellwagen Bank National Marine Sanctuary, part of the western North Atlantic Ocean feeding grounds. Recordings were made in 2006 and 2008. Song occurred during all months except February 2006 and June 2008. Song occurred most frequently in November for both years (mean $\pm \mathrm{SE}-2006$ : $18.26 \pm 0.66 \mathrm{~h}$ with song $\mathrm{d}^{-1}$; 2008: $18.59 \pm 0.82 \mathrm{~h}$ with song $\mathrm{d}^{-1}$ ). The longest song sessions occurred in April for both years $(2220 \pm 348,1430 \pm 274$ s, respectively) in November and December for 2006, and in May for 2008. This study demonstrates that song occurs often, when whales arrive at the feeding grounds in early April. The occurrence and length of song sessions decrease during July and August when whales are observed to be feeding in the sanctuary. Song occurrence and song session length increase when most males prepare to migrate southward in October to December. Such patterns are congruent with the hypothesis of seasonal hormonal activity and its potential role in song production.
\end{abstract}

KEY WORDS: Song $\cdot$ Feeding grounds $\cdot$ Humpback whale $\cdot$ Megaptera novaeangliae Resale or republication not permitted without written consent of the publisher

\section{INTRODUCTION}

Communication is an integral part of social behavior and its function has been studied extensively for many taxa such as insects, frogs, birds, bats, and cetaceans. At least some species in each of these taxa have complex social systems with potentially sophisticated communication mechanisms (Janik \& Slater 1997). An example of a sophisticated mechanism is singing, a behavior during which a species produces long, repetitive, vocal signals that can change considerably over time. Complex singing behavior is observed in many species, primarily in birds (e.g. Read \&
Weary 1992, Catchpole \& Slater 1995) as well as some marine mammal species (e.g. Payne \& McVay 1971, Oleson et al. 2007, Stafford et al. 2008). Song occurrence typically peaks during the breeding season, is usually highly seasonal in occurrence, and assumes a less structured form, or disappears altogether outside of the breeding season (Brenowitz et al. 1997, Stafford et al. 2001, Van Opzeeland et al. 2010).

Humpback whales Megaptera novaeangliae are known to produce a wide variety of non-song vocalizations, which include social and feeding calls (Silber 1986, Stimpert et al. 2007, Dunlop et al. 2008), in addition to their complex, repetitive, patterned song 
(Payne \& McVay 1971). Songs are only sung by male humpback whales and are mostly heard during the winter breeding season (Winn \& Winn 1978). It has been shown in bird song studies that male singers vocalize to exclude males, attract females to mate with them, and/or stimulate female reproductive behavior and physiology (Kroodsma \& Byers 1991). Similarly to bird song, humpback whale song likely has more than one function. The predominant explanations include the purposes of mating, serving to attract prospective female mates and/or establish dominance among males (Tyack 1981, Darling \& Berube 2001). Males within the same population display similar songs, which supports the notion that some form of vocal learning results in a common song that can sometimes change drastically over time, while at other times changing more gradually and progressively (Payne et al. 1983, Noad et al. 2000).

Most humpback whales migrate annually between summer feeding areas in colder temperate waters and winter breeding grounds in tropical waters (Dawbin 1966). In the western North Atlantic Ocean, humpback whales breed in the West Indies in Caribbean waters (Martin et al. 1984). During early spring, they leave their breeding grounds, migrate towards higher latitudes and feed in several regions including the Gulf of Maine, Eastern Canada, Western Greenland, Iceland and Norway (Katona \& Beard 1990, Smith et al. 1999). Humpback whales routinely use the waters within the Stellwagen Bank National
Marine Sanctuary (SBNMS), situated in the southern part of the Gulf of Maine, from April through December to feed on sand lance Ammodytes spp. (Overholtz \& Nicolas 1979).

Although song is primarily linked with breeding areas, studies have detected humpback whale songs at higher latitudes outside of breeding grounds. In these studies, songs have been recorded both on migration (Clapham \& Mattila 1990, Norris et al. 1999, Charif et al. 2001) and over short time periods on feeding grounds (Baker et al. 1985, Mattila et al. 1987, McSweeney et al. 1989, Clark \& Clapham 2004). For instance, Clark \& Gagnon (2004) used an ocean basin sound surveillance system (SOSUS) array to document protracted, 6 mo seasonal singing patterns during migration throughout the western North Atlantic. Charif et al. (2001) showed similar patterns of singing in the eastern North Atlantic and discovered a previously unknown migratory pathway off the British Isles.

McSweeney et al. (1989) recorded humpback whale songs on the southeast Alaskan feeding grounds in August 1979 and September 1981, the first known complete humpback whale songs recorded on any feeding grounds. Mattila et al. (1987) opportunistically recorded songs in the months of March through November in the SBNMS and reported on the complete songs they found in the late autumn months. Clark \& Clapham (2004) recorded humpback whale songs in the Gulf of Maine slightly
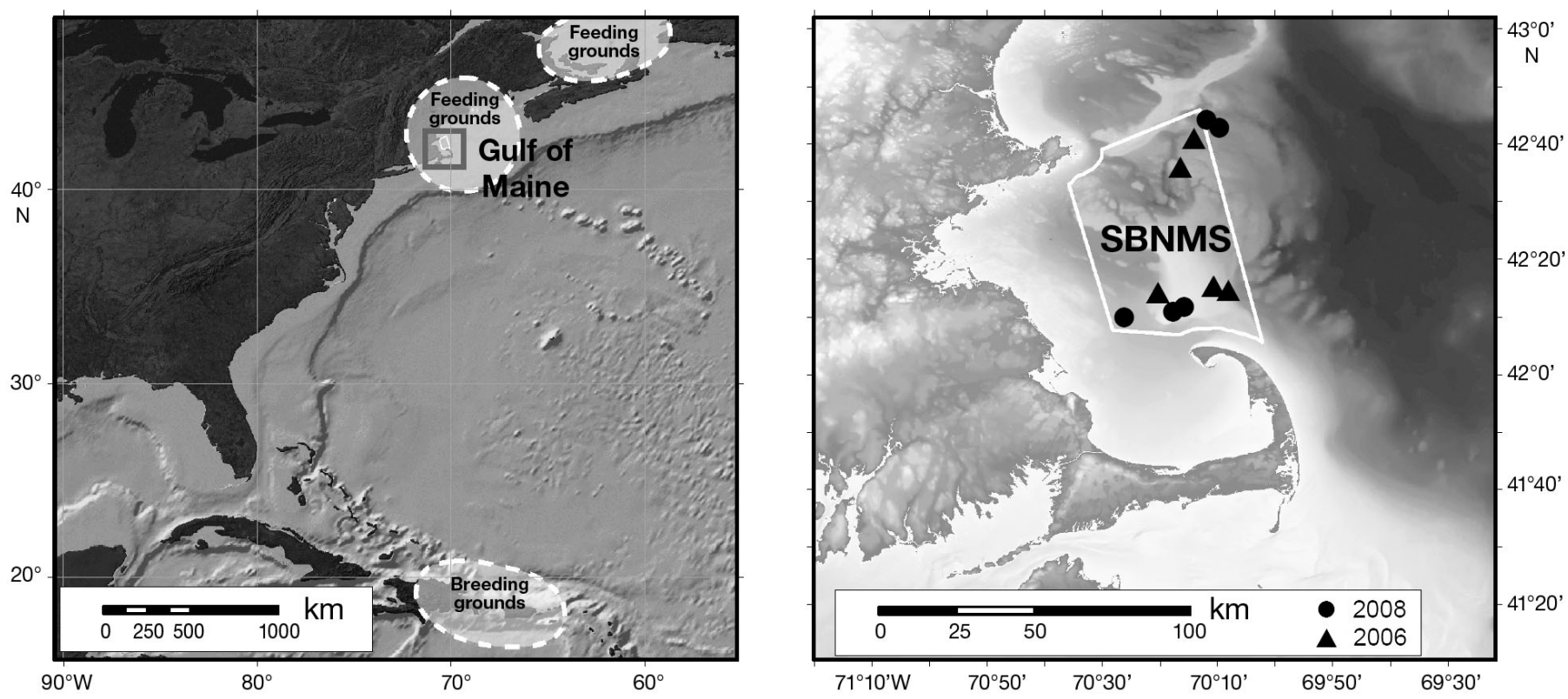

Fig. 1. (a) Locations of local breeding and feeding grounds of humpback whales that feed in the Gulf of Maine. Grey box = Stellwagen Bank National Marine Sanctuary (SBNMS). (b) Locations of marine acoustic recording units (MARUs) deployed in the SBNMS to record humpback whale song from January to December 2006 (A) and 2008 
to the east of SBNMS for $25 \mathrm{~d}$ from mid-May to early June. The evidence of song in high latitudes in 2 ocean basins demonstrates that humpback whale singing behavior is not confined to low latitude wintering grounds. However, these past studies offered only opportunistic or short-term recordings of humpback whale acoustic behavior and provide an incomplete snapshot of humpback whale songs outside of their breeding grounds. With 2 separate years of near continuous recordings, this study extends Clark \& Clapham's (2004) findings of recorded humpback whale songs heard from mid-May to early June in the Gulf of Maine region. The present study comprehensively evaluates songs on a feeding ground and is aimed at increasing our understanding of the frequency and function of song occurrence outside of breeding areas.

\section{MATERIALS AND METHODS}

Passive acoustic recordings were collected over 2 years, from January to December 2006 and 2008, throughout SBNMS $\left(42^{\circ} 33^{\prime} \mathrm{N}, 70^{\circ} 25^{\prime} \mathrm{W}\right)$ using marine acoustic recording units (MARUs) (Fig. 1a). MARUs are archival bottom-mounted acoustic recording units designed by the Cornell University's Laboratory of Ornithology Bioacoustics Research Program (BRP) for the purpose of continuously monitoring and recording marine sounds (www.birds.cornell.edu/brp/ hardware/pop-ups).

In 2006, 9 MARUs were deployed with an 8 nautical mile (n mile) inter-unit distance bounding an acoustically detected area of between 1500 to $1800 \mathrm{n}$ miles $^{2}$ in SBNMS. The MARUs recorded continuously at a sample rate of $2 \mathrm{kHz}$ for successive 3 mo periods. The MARU locations were selected to maximize coverage throughout the study and were deployed at roughly the same locations every 3 mo. In 2008, arrays of 10 MARUs were deployed between 3 to $6 \mathrm{n}$ miles apart for successive 3 mo periods. The 2008 MARU locations focused on marine mammal acoustic hotspots identified from the 2006 data as part of a larger scale effort to acoustically track marine mammals.

Humpback whale songs produce source levels ranging between 151 and $173 \mathrm{~dB}$ re $1 \mu \mathrm{Pa}$ (Au et al. 2006). SBNMS is a sufficiently small area that the same whale songs were present on 3 to 7 MARU recordings at any given time. Based on this, the decision was made to consider SBNMS as a single acoustic area for humpback whale songs. A cursory look at the 2006 data revealed that MARUs located to the west of Stellwagen Bank appeared to contain low quality record- ings of song and were likely acoustically shaded compared to MARUs to the north or east of the bank. Therefore, a single MARU was chosen for both years for each 3 mo deployment period from units to the north or east of the bank, with the chosen location being in the same area over both years (Fig. 1b). MARUs were not deployed in June 2006 and 2008 because of the high risk of loss due to heavy bottom trawling fishing activity. Reader are referred to Clark \& Clapham (2004) for data on the presence of humpback whale song in June. Other gaps in recordings indicate the time needed to retrieve one array and deploy the next. These gaps range from 8 to $34 \mathrm{~d}$. Acoustic recordings were analyzed for song occurrence and song session length using the eXtensible BioAcoustic Tool (XBAT) (www.xbat.org).

\section{Song occurrence}

To analyze both years of data for song occurrence, an automated template detector based on spectrogram cross-correlation was constructed in XBAT using a single song unit found consistently throughout 2006 and 2008 songs (Fig. 2). These units were optimally selected after constructing receiver operating characteristic (ROC) curves for all candidate units from songs of each year. Data were processed for the presence of the identified song unit, and the occurrence of this unit was taken as a proxy of singing. All hours that contained the detections were reviewed in $1 \mathrm{~h}$ spectrograms by a human analyst. Each hour was scored for song presence or absence and used to calculate an index of hour per day with song. All detections containing false positives were removed from the data. The number of false negatives was evaluated in order to better understand the detector's efficiency. Six random days were selected out of each of the 11 available months under varying ambient noise conditions ( $\mathrm{n}=132$ over $2 \mathrm{yr}$ ), encompassing roughly $20 \%$ of the total data recorded. Each hour was reviewed manually and compared against each song unit that was missed by the template detector. Our results showed false negative detection errors of $11 \%$ in 2006 and $6 \%$ in 2008.

\section{Song session length}

Song session lengths of humpback whale song were analyzed in detail for the 6 random days selected per month. Based on consistent repeating patterns found in the recordings, sections of singing 


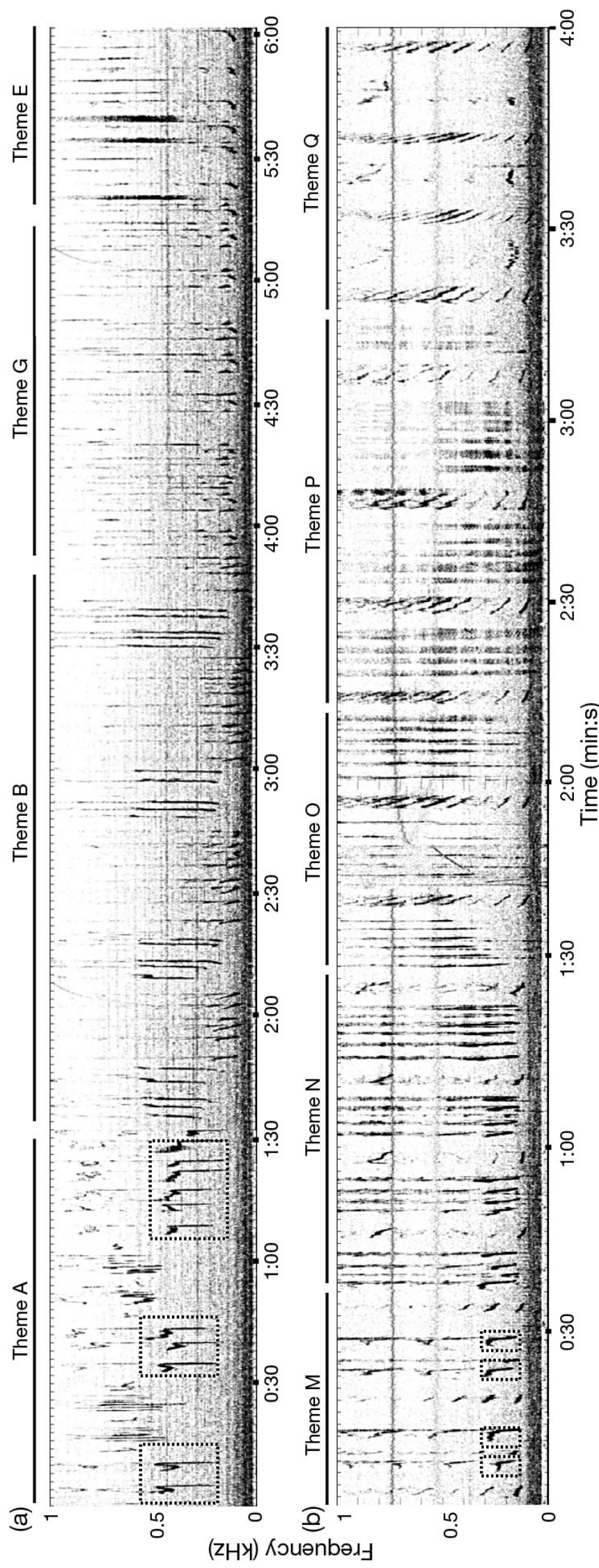

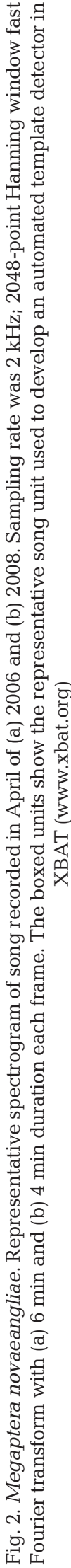

were divided into song sessions, which are composed of songs, made up of different themes, which are made up of phrases, and in turn made up of units (Payne \& McVay 1971). Songs were usually repeated without significant breaks. For the present study, song sessions were delineated by a significant gap of silence of at least $1 \mathrm{~min}$ (as in Guinee \& Payne 1988) due to the absence of a clear marker, such as the surface ratchet reported in previous studies (e.g. Cerchio et al. 2001, Fristrup 2003).

In order to document and compare seasonal variation in song session length, the duration of each song session was measured as the time from the start of the first unit of a song session to the end of the last unit in the song session; the end of the song session was considered the start of an interval of silence lasting at least one minute. Therefore, consecutive measures of song session length may potentially include many song sessions sung by the same individual. If more than one singer occurred in a period of singing, as visually detected by overlapping spectral units in the spectrogram, the sample was noted for song presence but was excluded from the song session length dataset due to the difficulty of determining where one male began or ended his song.

\section{Statistical analyses}

Non-parametric Kruskal-Wallis tests were used to compare song occurrence (h with song $\mathrm{d}^{-1}$ ) and song session length (s) over all months, since assumptions for parametric tests were not met; despite large sample sizes ( $\mathrm{n}>275$ for both analyses), data were not normally distributed. In addition, there is independence bias, because particularly vocal singers drive much of the variability in occurrence and song session length. Since only a single singer is usually heard at any time, and since it is impossible to quantify how many individuals actually contribute to the song heard in SBNMS, this bias cannot be avoided. 


\section{RESULTS}

\section{Song occurrence}

Song occurred during all recording months (i.e. excluding June) in both years except for February 2006 (158 d with song out of 319 recording $d$ in 2006; $144 \mathrm{~d}$ with song out of 276 recording $d$ in 2008) (Fig. 3). There were more instances of singing from April to May and October to December. Some differences between years were apparent in the occurrence of song. Song was present over $15 \mathrm{~d}$ in August 2006 but only 2 d in August 2008, and over 21 d in January 2008, but only 1 d in January 2006. Song was heard on only a few days in March and July for both years. Song occurrence differed significantly between months in both years $\left(\chi_{2006}^{2}=203.2, \mathrm{df}=11\right.$, $\left.\mathrm{p}<0.001 ; \chi_{2008}^{2}=208.6, \mathrm{df}=11, \mathrm{p}<0.001\right)$. From post hoc pairwise Mann-Whitney $U$-tests with Bonferroni corrections, it was determined that song occurrence was highest in November for both years, with April 2006 and 2008, December 2006 and October 2008 also having high levels of occurrence (Table 1).

\section{Song session length}

Song session length differed significantly between months in both years (Kruskal-Wallis $\chi_{2006}^{2}=49.3$,

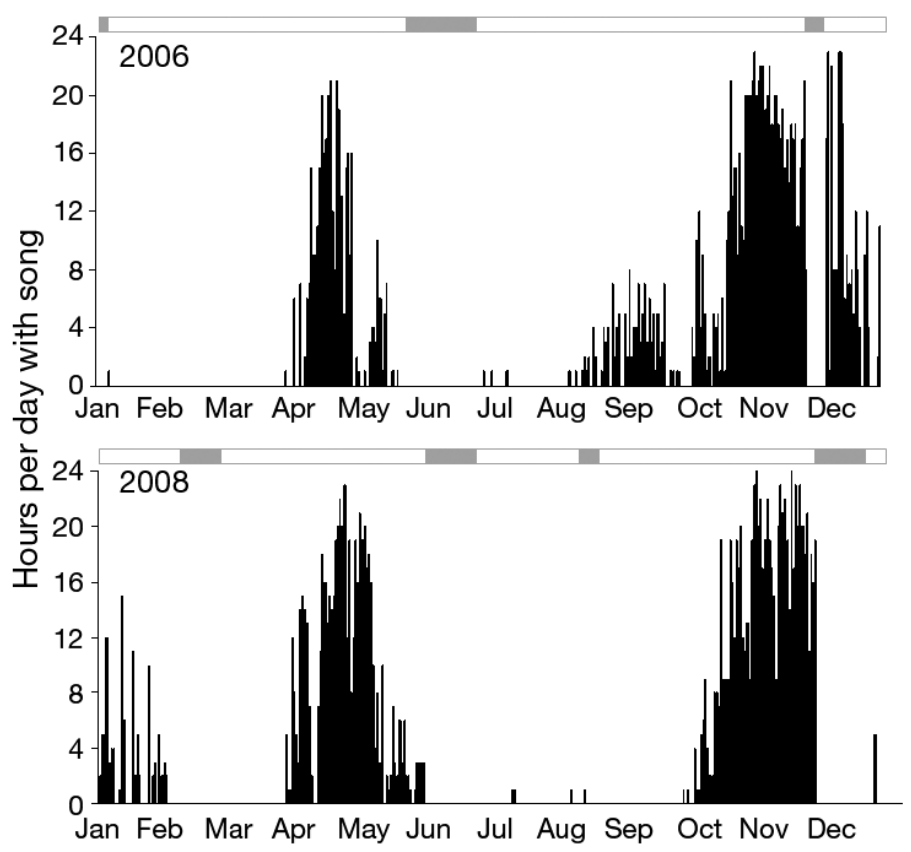

Fig. 3. Megaptera novaeangliae. Song occurrence in 2006 and 2008. Gray-shaded areas in top bar: no data $\mathrm{df}=7, \mathrm{p}<0.001$; Kruskal-Wallis $\chi_{2008}^{2}=44.8, \mathrm{df}=6$, $\mathrm{p}<0.001$ ) (Fig. 4). Based on post hoc pairwise MannWhitney $U$-tests with Bonferroni corrections, song sessions were longest in April of both years, November and December exhibited long song sessions in 2006, and May exhibited long song sessions in 2008 (Table 1). In some months of detected song occurrence, there were poor quality recordings or too few data to derive a meaningful measure of song session. Within a total of $262 \mathrm{~h}$ of measured song sessions, single singers were predominant throughout the year, with multiple singers ( 2 or 3 ) detected for a total of $44 \mathrm{~h}(17 \%)$. Multiple singers were only present in April, October, November and December when both song occurrence and song session length were highest.

\section{DISCUSSION}

This study shows that the occurrence of humpback whale song is pervasive and can be heard throughout the year, over at least 2 years, on a mid-latitude feeding ground. Intensive humpback whale singing occurs over protracted periods in spring and fall in the SBNMS feeding area, while small amounts of singing occur throughout the whole year. These results expand considerably upon our previous understanding of song occurrence for this area, where previous detection was mainly confined to mid-May, early June, or November (Mattila et al. 1987, Clark \& Clapham 2004). Our passive acoustic monitoring in SBNMS has provided fine-scale, year-round information demonstrating that humpback whale singing activity, albeit low compared to breeding ground singing activity, is most likely not an unusual occurrence in this area but rather a yearly persistent event. These results add to the growing body of literature that demonstrate the persistent presence of humpback whale song on migratory pathways and feeding grounds (e.g. McSweeney et al. 1989, Charif et al. 2001).

The occurrence of song in the SBNMS area was not uniform throughout the year. The highest occurrence of song and longest song sessions were generally heard from April to May and October to December, with marked waning in occurrence and song session length from June to September and January to March. This variability in song occurrence and song session length could be driven by 2 different causes. The first is seasonal variation in the amount of singing by male humpback whales, and the second is variation in the actual abundance of male singers in the area. 
Table 1. Summary of humpback whale song occurrence and song session length. (-): no data or quality too low for analysis

\begin{tabular}{|c|c|c|c|c|c|c|c|c|c|}
\hline \multirow[t]{2}{*}{ Month } & \multirow{2}{*}{$\begin{array}{c}\text { No. of } \\
\text { recording days }\end{array}$} & \multirow{2}{*}{$\begin{array}{l}\text { No. of days } \\
\text { with song }\end{array}$} & \multicolumn{3}{|c|}{ No. of hours with song per day } & \multirow{2}{*}{$\begin{array}{l}\text { No. of song } \\
\text { sessions }\end{array}$} & \multicolumn{3}{|c|}{ Song session length (s) } \\
\hline & & & Min. & Max. & Mean \pm SE & & Min. & Max. & Mean \pm SE \\
\hline \multicolumn{10}{|l|}{2006} \\
\hline Jan & 25 & 1 & 1 & 1 & $0.04 \pm 0.04$ & - & - & - & - \\
\hline Feb & 28 & 0 & 0 & 0 & 0 & - & - & - & - \\
\hline Mar & 31 & 1 & 1 & 1 & $0.03 \pm 0.03$ & - & - & - & - \\
\hline Apr & 30 & 25 & 2 & 21 & $10.50 \pm 1.27$ & 52 & 64 & 11978 & $2220 \pm 348$ \\
\hline May & 23 & 14 & 1 & 10 & $2.13 \pm 0.57$ & 21 & 90 & 1143 & $418 \pm 55$ \\
\hline Jun & 2 & 1 & 1 & 1 & $0.50 \pm 0.50$ & - & - & - & - \\
\hline Jul & 31 & 2 & 1 & 1 & $0.06 \pm 0.04$ & 5 & 57 & 539 & $240 \pm 96$ \\
\hline Aug & 31 & 15 & 1 & 7 & $1.26 \pm 0.32$ & 9 & 67 & 2774 & $577 \pm 291$ \\
\hline Sep & 30 & 24 & 1 & 8 & $3.03 \pm 0.46$ & 19 & 89 & 1828 & $443 \pm 106$ \\
\hline Oct & 31 & 26 & 1 & 21 & $7.35 \pm 1.16$ & 35 & 61 & 4262 & $891 \pm 185$ \\
\hline Nov & 27 & 27 & 8 & 23 & $18.26 \pm 0.66$ & 114 & 25 & 12818 & $1641 \pm 193$ \\
\hline Dec & 30 & 22 & 1 & 23 & $8.00 \pm 1.41$ & 41 & 36 & 22287 & $1831 \pm 569$ \\
\hline \multicolumn{10}{|l|}{2008} \\
\hline Jan & 31 & 21 & 1 & 15 & $3.42 \pm 0.70$ & 82 & 55 & 2625 & $327 \pm 42$ \\
\hline Feb & 16 & 1 & 2 & 2 & $0.13 \pm 0.13$ & 14 & 108 & 797 & $437 \pm 53$ \\
\hline Mar & 24 & 5 & 1 & 12 & $1.29 \pm 0.63$ & 1 & 182 & 182 & 182 \\
\hline Apr & 30 & 28 & 2 & 23 & $13.57 \pm 1.17$ & 74 & 42 & 13459 & $1430 \pm 274$ \\
\hline May & 28 & 26 & 1 & 20 & $5.57 \pm 1.08$ & 21 & 64 & 3381 & $1368 \pm 240$ \\
\hline Jun & 5 & 0 & 0 & 0 & 0 & - & - & - & - \\
\hline Jul & 31 & 2 & 1 & 1 & $0.06 \pm 0.04$ & - & - & - & - \\
\hline Aug & 23 & 2 & 1 & 1 & $0.09 \pm 0.06$ & - & - & - & - \\
\hline Sep & 22 & 5 & 1 & 4 & $0.36 \pm 0.19$ & - & - & - & - \\
\hline Oct & 31 & 33 & 2 & 24 & $13.26 \pm 1.19$ & 110 & 37 & 7117 & $800 \pm 112$ \\
\hline Nov & 22 & 22 & 9 & 24 & $18.59 \pm 0.82$ & 146 & 37 & 11194 & $623 \pm 95$ \\
\hline Dec & 13 & 1 & 5 & 5 & $0.38 \pm 0.38$ & - & - & - & \\
\hline
\end{tabular}

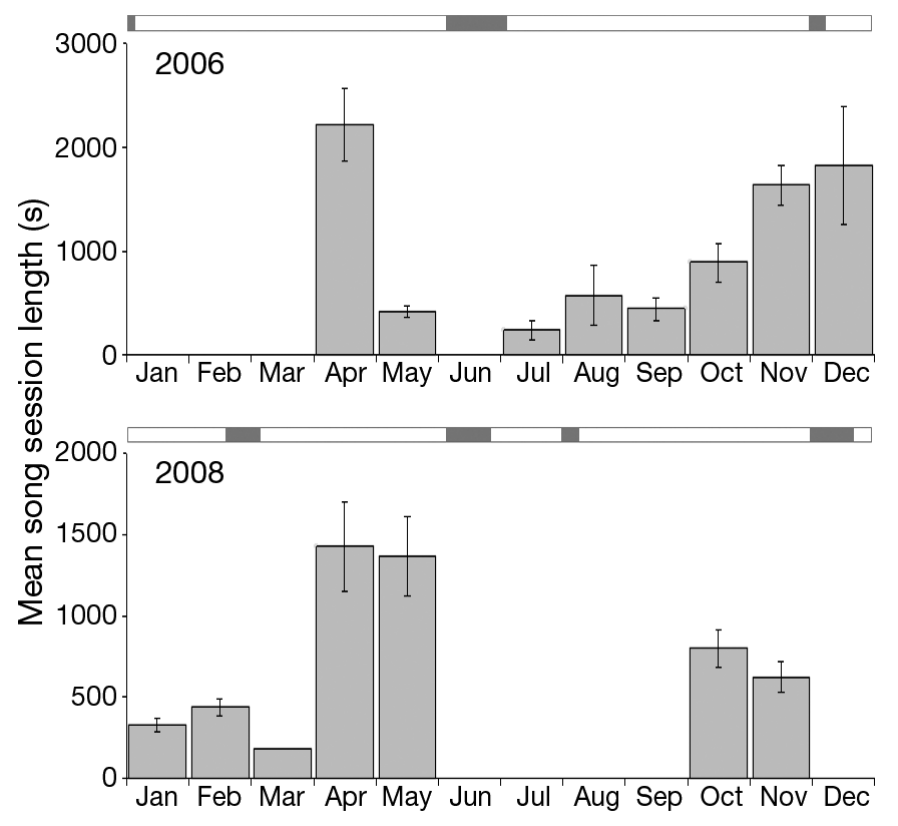

Fig. 4. Megaptera novaeangliae. Song session length. Greyshaded areas in top bar: no data. Each bar represents the monthly mean $( \pm \mathrm{SE})$ song session length based on 6 randomly selected $\mathrm{d} \mathrm{mo}^{-1}$. Note the different $y$-axes scales. For sample sizes see Table 1
In SBNMS, the number of singers acoustically detected in the area at a given time was consistently low (maximum of 3 singers in the array). This predominance in the number of solo singers was also detected in a separate study on a high-latitude feeding ground in southeastern Alaska (Gabriele \& Frankel 2002), which contrasts markedly with the much larger number of simultaneous, chorusing singers on tropical breeding grounds. We detected no clear increase in simultaneous singers like that observed on SOSUS sensors in deep offshore waters in the western North Atlantic where there was a peak in the daily number of singers from January to May (Clark \& Gagnon 2004). Therefore, a dramatic change in the number of male singers does not appear to drive the seasonal variation observed in SBNMS. However, the presence of male singers outside of the main April-May and October-December feeding ground singing periods demonstrates that a single individual male's motivation to stay within SBNMS likely drives some of the observed presence of song during the months of sparse song.

Humpback whale sighting rates (a measure of humpback whale abundance without correction for 
sex ratio) are highest from May to October and lowest from November to April (Robbins 2007). The May increase in humpback whales identifies the time period when most whales arrive on the SBNMS feeding grounds. This increase in humpback whale abundance reflects their use of SBNMS to forage on sand lance Ammodytes spp. as their primary prey (e.g. Hain et al. 1982, Payne et al. 1990, Clapham et al. 1993, Friedlaender et al. 2009, Hazen et al. 2009). Interestingly, although the mean number of whales present in SBNMS increases from April (15 ind. $\mathrm{n}$ mile $^{-1}$ ) to May (81 ind. $\mathrm{n} \mathrm{mile} \mathrm{e}^{-1}$ ), no more than 3 singers were acoustically detected at the same time within SBNMS. In June, humpback whale presence in the area does not wane, as evidenced by their high abundance in SBNMS (117 to 160 ind. $\mathrm{n}$ mile $^{-1}$, Robbins 2007). In the present study, males seem to travel from their breeding grounds along migration routes and arrive while still in the habit of singing full song. However, males decrease their singing or stop altogether, presumably to concentrate on feeding on sand lance instead. Towards late autumn, the mean number of humpback whales present in SBNMS decreases sharply to 70 (October) and 10 ind. $\mathrm{n} \mathrm{mile}{ }^{-1}$ (November), as most whales travel back to the Caribbean breeding grounds. Despite this decrease in numbers, male singing increases in early October and carries on through December.

Clark \& Clapham (2004) suggested that singing on feeding grounds may be driven by elevated testosterone levels in spring and autumn, and depressed levels in mid summer, similar to the welldocumented hormonal control of the avian song control system (Brenowitz 2004). Alongside the documented seasonal change in humpback whale testes (Chittleborough 1955), the results of our study are congruent with the hypothesis of a seasonal cycle of hormones and its potential role in humpback whale song production. Residual hormonal activity from the end of the breeding period in spring could account for the increased detection of singing in the spring months, and an expected decrease in hormonal activity could result in decreased song in mid-summer. The autumn increase in song could be attributed to increases in hormonal activity prior to the onset of the breeding season. This hypothesis was discussed recently (Wright \& Walsh 2010) with the assertion that there is a seasonal neurological change associated with humpback whale song production. While our study supports Wright \& Walsh's (2010) hypotheses, it is important to note that singing still occurs outside of breeding seasons in the present study, and the hypothesized change in neurological activity should not preclude the production of complete songs.

Singing males in 2008 were even present throughout January and early February. This demonstrates that males start to display song well before they have reached their breeding sites. It also suggests that not all males necessarily travel to their breeding grounds, either choosing to travel there late or not at all. The year-round presence of males in SBNMS with protracted singing possibly substantiates Clark \& Clapham's (2004) suggestions that song represents lowcost opportunistic advertisement by males to either allow assessment of males by females and/or to immediately court females who failed to conceive the previous winter. These hypotheses assume that male singing occurs in the presence of females. This requires that the females remain on feeding grounds during winter. In fact, Brown et al. (1995) demonstrated that female humpback whales do not migrate in certain years, most likely because they choose to stay on their feeding grounds and increase their body condition.

It is important to realize that partial and full humpback whale song is also present on recordings from more northerly feeding grounds off the Scotian Shelf, the British Isles, Eastern Greenland and Iceland throughout the winter (Charif et al. 2001, S. Nieukirk pers. comm.). Therefore, protracted and structured singing on a feeding site is not simply a phenomenon demonstrated by male humpback whales on the southernmost feeding ground. The pattern of semiannual peaks in song has also been detected by passive acoustic arrays in the Pacific Ocean off the coast of southern California (J. Hildebrand pers. comm.) which suggests that this pattern exists in different ocean basins and is governed by geographically separate but temporally synchronous mechanisms.

Studies of humpback whale song structural changes on both the breeding grounds and migration routes have shown that song in these areas can show both gradual as well as rapid punctuated change (Payne \& Payne 1985, Noad et al. 2000, Cerchio et al. 2001). McSweeney et al. (1989) showed that, for whales on Alaskan feeding grounds, songs contain all the same material, sung in the same order, as that heard off Mexico and Hawaii in the surrounding wintering seasons. However, song, theme and some phrase durations are abbreviated in the Alaskan songs. Mattila et al. (1987) provided spectrograms of representative phrases within complete songs from both SBNMS and the West Indies, and noted similarity but did not perform extensive quantitative analyses. Therefore, detailed analyses of humpback whale song structure 
within SBNMS over multiple years as well as comparative analyses between the song in the West Indies and SBNMS may help to further elucidate when and where song changes in structure occur, and which components of the songs heard on the feeding grounds make up part of the final breeding ground songs.

The present study has presented seasonal patterns in non-breeding ground song occurrence and such patterns will become more clear as passive acoustic monitoring of SBNMS continues in the long term. The results of this study are largely congruent to the hypothesis of seasonal hormonal cycles having a role in song production but also provoke investigation of the general plasticity of humpback whale song production in an area where animals are given an incentive to exhibit feeding behavior (and consequently, feeding vocalizations) instead. Understanding the feeding/breeding behavior dichotomy requires future investigation of song production in relation to feeding call production and how they relate to environmental and physiological conditions.

Acknowledgements. The authors thank the Bioacoustics Research Program at the Cornell Laboratory of Ornithology and the Protected Species Branch of the Northeast Fisheries Science Center in Woods Hole, Massachusetts, for field work and analysis support. We thank A. Chang, M. Hansen, and G. Poritz for statistical analysis support and P. Oboyski and S. Cole for comments. We thank J. Tougaard for providing helpful tools for preliminary song structure analyses. This project was completed under the support of the NOAA Ernst Hollings Scholarship Program while attending the University of California, Berkeley (E.T.V.). Funding for this project was provided by Cornell University, NOAA Northeast Fisheries Science Center, Northeast Regional Office, and Stellwagen Bank National Marine Sanctuary via the National Oceanographic Partnership Program (NOPP). We give special thanks to Dr. S. Cerchio for insightful and detailed comments as well as 2 anonymous referees who helped to significantly improve this paper.

\section{LITERATURE CITED}

Au WWL, Pack AA, Lammers MO, Herman LM, Deakos $\mathrm{MH}$, Andrews K (2006) Acoustic properties of humpback whale songs. J Acoust Soc Am 120:1103-1110

Baker CS, Herman LM, Perry A, Lawton WS, Straley JM, Straley JH (1985) Population characteristics and migration of summer and late-season humpback whales (Megaptera novaeangliae) in southeastern Alaska. Mar Mamm Sci 1:304-323

Brenowitz EA (2004) Plasticity of the adult avian song control system. Ann N Y Acad Sci 1016:560-585

- Brenowitz EA, Margoliash D, Nordeen KW (1997) An introduction to birdsong and the avian song system. J Neurobiol 33:495-500

Brown MR, Corkeron PJ, Hale PT, Schultz KW, Bryden MM (1995) Evidence for a sex-segregated migration in the humpback whale (Megaptera novaeangliae). Proc Biol Sci 259:229-234

Catchpole CK, Slater PJB (1995) Bird song: biological themes and variations. Cambridge University Press, Cambridge

Cerchio S, Jacobsen JK, Norris TF (2001) Temporal and geographical variation in songs of humpback whales, Megaptera novaeangliae: synchronous change in Hawaiian and Mexican breeding assemblages. Anim Behav 62:313-329

> Charif RA, Clapham PJ, Clark CW (2001) Acoustic detections of singing humpback whales in deep waters off the British Isles. Mar Mamm Sci 17:751-768

Chittleborough RG (1955) Aspects of reproduction in the male humpback whale, Megaptera nodosa (Bonnaterre). Aust J Mar Freshwater Res 6:1-29

Clapham PJ, Mattila DK (1990) Humpback whale songs as indicators of migration routes. Mar Mamm Sci 6:155-160

Clapham PJ, Baraff LS, Carlson CA, Christian MA and others (1993) Seasonal occurrence and annual return of humpback whales, Megaptera novaeangliae, in the southern Gulf of Maine. Can J Zool 71:440-443

Clark CW, Clapham PJ (2004) Acoustic monitoring on a humpback whale (Megaptera novaeangliae) feeding ground shows continual singing into late spring. Proc Biol Sci 271:1051-1057

Clark CW, Gagnon GC (2004) Low-frequency vocal behaviors of baleen whales in the North Atlantic: insights from IUSS detections, locations and tracking from 1992 to 1996. US Nav J Underw Acoust 52:609-640

Darling JD, Berube M (2001) Interactions of singing humpback whales with other males. Mar Mamm Sci 17: 570-584

Dawbin WH (1966) The seasonal migratory cycle of humpback whales. In: Norris KS (ed) Whales, dolphins and porpoises. University of California, Berkeley, p 145-170

> Dunlop RA, Cato DH, Noad MJ (2008) Non-song acoustic communication in migrating humpback whales (Megaptera novaeangliae). Mar Mamm Sci 24:613-629

Friedlaender AS, Hazen EL, Nowacek DP, Halpin PN and others (2009) Diel changes in humpback whale Megaptera novaeangliae feeding behavior in response to sand lance Ammodytes spp. behavior and distribution. Mar Ecol Prog Ser 395:91-100

Fristrup KM (2003) Variation in humpback whale (Megaptera novaeangliae) song length in relation to low-frequency sound broadcasts. J Acoust Soc Am 113:3411-3424

Gabriele CM, Frankel AS (2002) The occurrence and significance of humpback whale songs in Glacier Bay, Southeastern Alaska. Arct Res US 16:42-47

- Guinee LN, Payne K (1988) Rhyme-like repetitions in songs of humpback whales. Ethology 79:295-306

Hain JHW, Carter GR, Kraus SD, Mayo CA, Winn HE (1982) Feeding behavior of the humpback whale, Megaptera novaeangliae, in the Western North Atlantic. Fish Bull 80:259-268

> Hazen EL, Friedlaender AS, Thompson MA, Ware CR, Weinrich MT, Halpin PN, Wiley DN (2009) Fine-scale prey aggregations and feeding ecology of humpback whales Megaptera novaeangliae. Mar Ecol Prog Ser 395:75-89

> Janik VM, Slater PJB (1997) Vocal learning in mammals. Adv Stud Behav 26:59-99

Katona SK, Beard JA (1990) Population size, migrations and feeding aggregations of the humpback whale (Megaptera novaeangliae) in the western North Atlantic Ocean. Rep Int Whal Comm Spec Issue 12:295-305 
Kroodsma DE, Byers BE (1991) The function(s) of bird song. Am Zool 31:318-328

Martin AR, Katona SK, Mattila DK, Hembree D, Waters TD (1984) Migration of humpback whales between the Caribbean and Iceland. J Mammal 65:330-333

Mattila DK, Guinee LN, Mayo CA (1987) Humpback whale songs on a North Atlantic feeding ground. J Mammal 68: 880-883

McSweeney DJ, Chu KC, Dolphin WF, Guinee LN (1989) North Pacific humpback whale songs: a comparison of Southeast Alaskan feeding ground songs with Hawaiian wintering ground songs. Mar Mamm Sci 5:139-148

Noad MJ, Cato DH, Bryden MM, Jenner MN, Jenner KCS (2000) Cultural revolution in whale songs. Nature 408:537

> Norris TF, Mc Donald M, Barlow J (1999) Acoustic detections of singing humpback whales (Megaptera novaeangliae) in the eastern North Pacific during their northbound migration. J Acoust Soc Am 106:506-514

Oleson EM, Calambokidis J, Burgess WC, McDonald MA, LeDuc CA, Hildebrand JA (2007) Behavioral context of call production by eastern North Pacific blue whales. Mar Ecol Prog Ser 330:269-284

Overholtz WJ, Nicolas JR (1979) Apparent feeding by the fin whale, Balaenoptera physalus, and humpback whale, Megaptera novaeangliae, on the American sand lance, Ammodytes americanus, in the northwest Atlantic. Fish Bull (Wash DC) 77:285-287

Payne RS, McVay S (1971) Songs of the humpback whale. Science 173:585-597

Payne K, Payne R (1985) Large scale changes over 19 years in songs of humpback whales in Bermuda. Z Tierpsychol 68:89-114

Payne K, Tyack P, Payne R (1983) Progressive changes in the song of humpback whales (Megaptera novaeangliae): a detailed analysis of two seasons in Hawaii. In: Payne $\mathrm{R}$ (ed) Communication and behavior of whales. Westview Press, Boulder, CO, p 9-57

Payne PM, Wiley DN, Young SB, Pittman S, Clapham PJ,

Editorial responsibility: Christine Paetzold, Oldendorf/Luhe, Germany
Jossi JW (1990) Recent fluctuations in the abundance of baleen whales in the southern Gulf of Maine in relation to changes in selected prey. Fish Bull (Wash DC) 88:687-696

Read AF, Weary DM (1992) The evolution of bird song: comparative analyses. Philos Trans R Soc Lond B 338:165-187

Robbins J (2007) Structure and dynamics of the Gulf of Maine humpback whale population. PhD thesis, University of St. Andrews, Scotland

Silber GK (1986) The relationship of social vocalizations to surface behavior and aggression in the Hawaiian humpback whale (Megaptera novaeangliae). Can J Zool 64: 2075-2080

Smith TD, Allen J, Clapham PJ, Hammond PS and others (1999) An ocean-basin-wide mark-recapture study of the North Atlantic humpback whale (Megaptera novaeangliae). Mar Mamm Sci 15:1-32

Stafford KM, Nieukirk SL, Fox CG (2001) Geographic and seasonal variation of blue whale calls in the North Pacific. J Cetacean Res Manag 3:65-76

Stafford KM, Moore SE, Laidre KL, Heide-Jorgensen MP (2008) Bowhead whale springtime song off West Greenland. J Acoust Soc Am 124:3315-3323

Stimpert AK, Wiley DN, Au WWL, Johnson MP, Arsenault R (2007) 'Megapclicks': acoustic click trains and buzzes produced during night-time feeding of humpback whales (Megaptera novaeangliae). Biol Lett 3:467-470

$>$ Tyack P (1981) Interactions between singing Hawaiian humpback whales and conspecifics nearby. Behav Ecol Sociobiol 8:105-116

> Van Opzeeland I, Van Parijs SM, Bornemann H, Frickenhaus S and others (2010) Acoustic ecology of Antarctic pinnipeds. Mar Ecol Prog Ser 414:267-291

> Winn HE, Winn LK (1978) The song of the humpback whale Megaptera novaeangliae in the West-Indies. Mar Biol 47: 97-114

Wright AJ, Walsh LA (2010) Mind the gap: why neurological plasticity may explain seasonal interruption in humpback whale song. J Mar Biol Assoc UK 90:1489-1491

Submitted: October 18, 2010; Accepted: October 27, 2011 Proofs received from author(s): December 14, 2011 